\title{
Configurações
}

Revista Ciências Sociais

$14 \mid 2014$

Para além da Governação. Políticas, práticas e discursos de inclusão e promoção da diversidade cultural

\section{Multiculturalismo, pluralismo cultural y interculturalidad en el contexto de América Latina: la presencia de los pueblos originarios}

Multiculturalismo, pluralismo cultural e interculturalidade no contexto da América Latina: a presença dos povos originários

Multiculturalism, Cultural Pluralism and Interculturalism in the context of Latin America: the presence of Indigenous Peoples

Alicia M. Barabas

\section{(2) OpenEdition}

Edición electrónica

URL: http://journals.openedition.org/configuracoes/2219

DOI: $10.4000 /$ configuracoes. 2219

ISSN: 2182-7419

Editor

Centro de Investigação em Ciências Sociais

\section{Edición impresa}

Paginación: 11-24

ISBN: 1646-5075

ISSN: 1646-5075

\section{Referencia electrónica}

Alicia M. Barabas, « Multiculturalismo, pluralismo cultural y interculturalidad en el contexto de América Latina: la presencia de los pueblos originarios », Configurações [En línea], 14 | 2014, Publicado el 25 marzo 2015, consultado el 21 diciembre 2020. URL : http://journals.openedition.org/ configuracoes/2219; DOI : https://doi.org/10.4000/configuracoes.2219 


\title{
Multiculturalismo, pluralismo cultural $y$ interculturalidad en el contexto de América Latina: la presencia de los pueblos originarios
}

\author{
Multiculturalismo, pluralismo cultural e interculturalidade no contexto da \\ América Latina: a presença dos povos originários \\ Multiculturalism, Cultural Pluralism and Interculturalism in the context of \\ Latin America: the presence of Indigenous Peoples
}

\author{
Alicia M. Barabas
}

Este trabajo constituye un modesto intento, dada la gran cantidad de literatura sobre el tema y las diferentes aproximaciones interdisciplinarias, por precisar los significados de los conceptos multiculturalismo, pluralismo cultural e interculturalidad, tan en boga hoy en día, para arribar a un uso terminológico más apropiado desde la perspectiva antropológica, ilustrado por una panorámica de la diversidad cultural en algunos países de América Latina.

2 Através de las palabras de algunos pensadores, en los que ahora poco podré detenerme ${ }^{1}$, parece claro que multiculturalismo ha sido usado para referirse a tres cuestiones diferentes: la existencia de múltiples culturas, la ideología de respeto y convivencia de múltiples culturas, y una política implementada por los gobiernos, principalmente de Europa y Norte América, sobre todo en relación con los inmigrantes. Aunque las dos primeras acepciones de multiculturalismo antes mencionadas son utilizadas como sinónimos de pluralismo cultural, éste es un concepto más usual en la antropología latinoamericana que intenta dar un lugar específico y diferencial a los pueblos originarios en los contextos de diversidad cultural. En cuanto a la interculturalidad, su uso en las ciencias sociales es ambiguo ya que tanto se refiere a la situación de contacto entre culturas diferentes, como a la ideología de la relación igualitaria entre ellas construida en 
el marco de la globalización y las políticas de derechos humanos. En estas páginas me aproximaré a estos conceptos partiendo de la base de que no podría desarrollarse la interculturalidad sin una plataforma multi o pluricultural.

\section{Multiculturalismo y pluralismo cultural}

3 En el uso actual más generalizado multiculturalismo suele entenderse como el reconocimiento de la coexistencia de grupos culturales diferentes, dentro de un mismo estado nacional. Así presentado no difiere sustancialmente de lo que en antropología llamamos pluralismo cultural desde hace décadas, y que se refiere a la pluralidad de culturas que conviven de hecho en el seno de estados nacionales (pluralismo de hecho). Sin embargo, multiculturalismo tiene otros significados diferentes a los del pluralismo cultural, más allá de la existencia de hecho de múltiples culturas diferentes, en el que coinciden.

4 Bhikhu Parekh (2004) señala que el movimiento multicultural apareció en los tempranos 1970 en Canadá y Australia, poco más tarde en Estados Unidos, Inglaterra, Alemania y Francia. Resulta interesante la historia que recoge Azurmendi (2002) acerca del surgimiento y controversia del multiculturalismo: concretamente el término lo acuñó el gobierno anglófono canadiense para referirse a una nueva política de finales de 1960, en el contexto del movimiento francófono canadiense, que tuviera en cuenta a las tres entidades sociales de la Federación: la anglófona, la francófona y la aborigen, siendo los anglófonos la mayoría étnica y las otras consideradas minorías étnicas. Más tarde la política multicultural se amplió hasta abarcar a los inmigrantes, considerados como minorías étnicas, y el concepto hizo referencia a las variadas ciudadanías segmentadas por cultura, lengua e historia que se hallan dentro de un estado democrático.

5 Al expandirse hacia otras situaciones, contextos y disciplinas, el multiculturalismo continuó tratando a todos los grupos diferentes como minorías. Como los inmigrantes se han transformado progresivamente en el foco de las políticas multiculturales, al hablar de minorías las políticas multiculturales se están refiriendo por lo general a esos grupos diversos demográficamente minoritarios que han arribado a diferentes contextos nacionales en épocas más o menos recientes.

6 El problema surge cuando bajo el concepto minoría se engloban también otros grupos sociales, como los pueblos originarios, asimismo llamados indígenas. Desde mi perspectiva debe distinguirse claramente a los inmigrantes (de diferentes orígenes étnicos) de las poblaciones aborígenes o autóctonas. Estas últimas fundan sus derechos en la ascendencia histórica y los vínculos territoriales milenarios. Los inmigrantes, al igual que otros grupos culturalmente diversos pero surgidos dentro de las dinámicas de conformación nacionales, no tienen historicidad ni territorialidad, previas a la conformación de los estados nacionales, aunque ciertamente tienen derecho a la reproducción de su diversidad dentro de estados multiculturales. De allí que los pueblos autóctonos no puedan ser catalogados como minorías dentro de una situación de multiculturalismo.

7 Esa profundidad histórica en los territorios que actualmente pertenecen a los estados nacionales la demuestran, entre otras evidencias, las muy numerosas rebeliones e insurrecciones contra los poderes coloniales y post-independentistas en toda América Latina (Barabas, 1989); procesos históricos en los que los pueblos indígenas han sido 
actores principales de la oposición al colonialismo y a los colonialismos internos. Su presencia contemporánea se manifiesta en los movimientos, que llamamos etnopolíticos (Barabas, 2005), generados en toda América desde 1960-1970 hasta la actualidad, cuando se adentraron en arenas políticas nacionales e internacionales a través de organizaciones civiles en defensa de derechos étnicos, culturales y territoriales. Los movimientos indios, organizados en asociaciones han tenido y tienen diferentes participaciones en los contextos nacionales, pero constituyen sujetos sociales hoy en día reconocidos, legalmente o no, por los estados nacionales.

El multiculturalismo ha sido considerado como la ideología social-política de la globalización y de la masificación de la migración internacional, al mismo tiempo que una disciplina humanística que en las aulas se expresó en los Estudios Culturales, convirtiéndose en el top académico en Estados Unidos de 1980, por ser el nuevo enfoque de los estudios norteamericanos sobre grupos étnicos. Sin embargo se trata de un término multivocal, que también puede ser entendido como un modo de tratar la diversidad cultural, un desafío moral, un tipo de política pública o cierta especie de característica del posmodernismo; aunque todos los autores coinciden en que se fundamenta en el reconocimiento público de derechos culturales dentro de un estado-nación.

Para Vertovec (2003), así como para muchos otros, el multiculturalismo ha sido ya asociado indisolublemente con el fenómeno migratorio transnacional de grupos etnoculturales o nacionales, que pasan a ser minorías étnicas en los ámbitos de migración. El término incluye nociones como reconocer los derechos a la diversidad cultural y la formación de nuevas comunidades, abandonar el supuesto de los estadosnación homogéneos y monoculturales, y vincular esos derechos con la igualdad social y la no discriminación. No obstante, dadas las experiencias concretas del multiculturalismo ligado con la globalización, que se funda en la idea de sumatoria de diversidades o mosaico cultural, para muchos autores lo que esta filosofía y práctica política han producido es segregación entre culturas, marginación y constitución de ghettos.

El concepto de multiculturalidad encontró sus raíces y soportes teóricos determinantes en la antropología a partir de los conceptos referenciales de cultura y relativismo cultural. Pero el concepto de cultura que manejó el multiculturalismo era estático, ya que la concebía como invariable, y esta concepción aunada a la del relativismo dio origen a una noción dominante de multiculturalismo que desvalorizaba los denominadores interculturales dinámicos. Los críticos, en cambio, piensan la cultura como en permanente transformación y construida a partir de denominadores comunes entre todas las diversidades. Por otra parte, en la historia de la antropología el relativismo surgió con la escuela boasiana, como reacción a la perspectiva etnocéntrica y hegemónica de los paradigmas evolucionista y psico-cultural, privilegiando la objetividad en la investigación de otras culturas a la par que actitudes de respeto por la identidad y las diferencias culturales. Se acepta del relativismo su postulado de igualdad de las culturas y respeto intercultural, lo que se critica es que el análisis de la cultura está cerrado sobre sí mismo sin comparación ni comunicación con otras, lo cual es contrario al multiculturalismo que propugna una comunicación intercultural y denominadores comunes e incluso hibridación. Precisamente, lo intercultural sería ese estar-transitar entre diferentes culturas.

11 Por otra parte, tanto pluralismo cultural como multiculturalismo hacen referencia también a la ideología y la política de respeto a la diversidad cultural. A diferencia del multiculturalismo, el pluralismo cultural tiene menos carga histórica e ideológica, y 
según Rouland, Pierré-Caps et al. (1990), tiene por objeto preservar la identidad de los grupos culturalmente diferentes, otorgándoles gran libertad en la administración de sus asuntos y tomando la forma del sistema de autonomía local, conciliada con la integración nacional. El pluralismo trata de unir a diferentes grupos etnoculturales en una relación de interdependencia, igualdad y respeto mutuo, al tiempo que cada uno desarrolla su propio modo de vida y cultura.

La especificidad histórica y contextual del multiculturalismo que etiqueta hoy en día a los inmigrantes culturalmente diferenciados, me inclina a proponer el uso preferente de pluralismo cultural, utilizado por la antropología desde la década de 1980, para referirnos a situaciones interculturales en las que estén presentes los pueblos originarios. Pluralismo cultural de hecho, para dar cuenta de la mera existencia de la diversidad cultural en un ámbito determinado, y pluralismo cultural de derecho, como la ideología social y política de reconocimiento y respeto a esa diversidad cultural, vinculada con las políticas de derechos humanos de los pueblos autóctonos; esto es una gobernanza de la diversidad. El pluralismo cultural de derecho no sólo aboga por el reconocimiento de la pluralidad de hecho, que ya existe en muchas constituciones nacionales, sino por la convivencia respetuosa y la comunicación igualitaria entre las culturas alternas dentro de los estados nacionales.

Desde mi perspectiva sería preferible referirnos a multiculturalismo para incluir a los inmigrantes de múltiples orígenes que habitan los estados nacionales latinoamericanos; poblaciones que no en todos los países son sujetos de políticas públicas específicas, y a los diversos grupos culturales internos, algunos de los cuales son sujetos de políticas públicas, y reservar pluralismo cultural para referirnos a los pueblos originarios, quienes en mayor o menor medida son sujetos de políticas públicas regionales y nacionales.

\section{Interculturalidad}

14 Interculturalidad es un término también muy en boga actualmente tanto en las ciencias sociales como en la sociedad civil en general y se refiere a la dinámica de las relaciones que se establecen en el contexto de la diversidad cultural. La pregunta por la interculturalidad ha sido entendida como occidental y eurocéntrica, así como inscripta en la lógica de una cultura científica en la que cada disciplina (pedagogía, literatura, política, sociología, filosofía, entre otras) la define y clasifica desde su perspectiva, dándole matices muy diferentes. Para diversos autores lo intercultural tiene que ver con prácticas culturales y modos de vida concretos de las personas que se ponen en interacción, en el entendido de que el campo de lo intercultural no está fuera de nosotros sino que estamos involucrados en él, y éste es el espacio -o transitabilidad- que se va creando mediante el diálogo y la comunicación entre culturas. El mecanismo que pone en acción la interculturalidad, que se piensa como la forma más desarrollada del diálogo de las culturas y las civilizaciones, es el diálogo intercultural.

La interculturalidad es una meta política que debe ejercerse en todos los ámbitos de la vida social, pero que se ha aplicado de manera especial en la educación indígena bilingüe intercultural en toda América Latina como la política educativa indígena oficial, desplazando a las políticas asimilacionistas e integracionistas que se llamaban bilingües, dando importancia al aprendizaje de la lengua y la cultura propias. Un tópico que ha ocupado a diversos estudiosos de la interculturalidad es el de la comunicación intercultural. La competencia comunicativa intercultural consiste en una habilidad comunicativa 
genérica que nos permite a todos ser flexibles, no dogmáticos y abiertos en la adaptación al reto de las interacciones interculturales; esto es, no reducir las nuevas experiencias a categorías preconcebidas y rechazar el etnocentrismo. Esta comunicación debe promover una reflexión crítica sobre nuestros valores y cultura y actitudes sin prejuicios hacia la diferencia, para lo cual es fundamental adquirir información sobre la historia, valores, instituciones y sistemas conductuales de la o las otras sociedades. Con la adquisición de competencia cultural sobre el "Otro" se posibilita la interculturalidad y se destruyen los estereotipos y prejuicios negativos que suelen ser producto de la ausencia o mala calidad de la información acerca de los estilos de vida de los otros culturales con los que se convive.

\section{La diversidad cultural en América Latina}

Esta breve panorámica de la diversidad cultural contemporánea en algunos países de Norte (México) y Sudamérica (Ecuador, Perú, Bolivia, Chile, Argentina y Brasil) intenta mostrar la presencia de los pueblos originarios en los contextos nacionales integrados también, hoy en día principalmente, por población no indígena; criollos, mestizos e inmigrantes de diferentes orígenes nacionales que reconocen -o no- pertenencias étnicas específicas (Barabas, 2014b). Los países de América Latina son plurales por su composición indígena y multiculturales por la presencia de grupos culturales diversos. En este artículo no nos referiremos a las poblaciones inmigrantes que reclaman pertenencias étnicas y derechos para su diversidad cultural, dado que los inmigrantes no conforman un sector homogéneo sino segmentado por los fenotipos, las clases y las culturas, y las problemáticas que sufren son objeto de estudios específicos. Vale aclarar que las cifras de población total y población indígena en cada uno de los países citados es una estimación aproximada sustentada en datos censales oficiales recientes (Wikipedia, 2014), que sólo intenta mostrar el peso específico de estos pueblos dentro de cada contexto nacional.

México es y ha sido un espacio etnocultural plural desde la época prehispánica en el que convivieron numerosos grupos etnolingüísticos diferenciados. La Colonia trajo el aporte involuntario de una pequeña población africana y la llegada de población blanca europea, en tanto que las migraciones de la historia contemporánea aportaron contingentes europeos, asiáticos y latinoamericanos. Dentro de un proceso histórico de contactos interculturales asimétricos se produjo la invisibilización simbólica y fáctica de los indios sobre los que se construyó, desde la época colonial, un imaginario y unas prácticas sociales racistas. En el siglo XX, el afianzamiento del estado concebido como mestizo trajo consigo las políticas asimilacionistas e integracionistas que buscaban la aculturación, la desaparición de lenguas vernáculas y la integración del indio a la identidad nacional (Oehmichen, 2014). En México, la suplantación de lo étnico por la condición de clase, proceso característico del mundo andino del siglo XX, se dio durante las décadas de 1970 y 1980 y fue patrimonio de un marxismo economicista, aunque tanto esta corriente como el indigenismo de estado y los partidos de izquierda coincidían en que lo indio debía desaparecer del contexto nacional. Un poco más tardíamente que en el resto de América Latina surgieron en México los movimientos etnopolíticos, tanto los promovidos por el estado como los independientes y los ligados con la iglesia progresista o con los partidos de izquierda. Fue sin duda a partir de 1994 con la insurrección del Ejército Zapatista de Liberación Nacional (EZLN) que se dinamizaron las identidades indígenas en todo México y esta revitalización cuajó en la formación de nuevas organizaciones etnopolíticas y del 
Congreso Nacional Indígena. La población total de México ascendía en 2010 a poco más de 112 millones de personas y la población indígena total a aproximadamente dieciséis millones de hablantes de alguna de sus sesenta y ocho lenguas, pero no obstante constituir el $10,9 \%$ de la población la reforma constitucional de 2001 fue totalmente insuficiente en relación con las demandas indígenas. México ha reconocido jurídicamente su composición pluricultural desde 1992 (Barabas, 1996, 2014a), pero se trata de un pluralismo desigual, de un reconocimiento sólo de hecho que contrasta con la pobreza, el racismo y la migración forzosa que sufren los pueblos indígenas. La gobernanza de esta pluralidad está limitada a la educación bilingüe intercultural y a la atención de la salud de la mujer indígena, en tanto que las diversas políticas públicas se planifican para la población rural y urbana catalogada como pobre, dentro de la que queda incluida la población indígena, desconociendo la especificidad cultural de los pueblos originarios.

En Bolivia se han producido transformaciones sustanciales desde el estado neoliberal de hegemonía criolla hasta las formas actuales de plasmar la ideología pluralista y acercarse a la utopía histórica de los indios evidenciada en numerosas rebeliones y proyectos autonómicos. Bolivia ha sido y es un país mayoritariamente indígena pero internamente muy diverso, con una mayoría aymara y menor caudal de quechuas en la región andina occidental y un alto número de pueblos indígenas pequeños (guaraní, chiquitano, mojeño) en las tierras bajas del norte y el oriente. Con diversos matices, los diferentes pueblos fueron sometidos primero a la situación colonial, más tarde a la legalidad criolla-mestiza de la independencia y por último, en 1952, a un proceso revolucionario que consolidó el estado nacionalista mestizo en el que se campesinizó y sindicalizó a todos los indígenas, ya que el estado pretendía borrar la diversidad etnocultural y lingüística. Este proceso no tan diferente del de Ecuador o Perú en cuanto a la concepción clasista sobre la población indígena en la mitad del siglo XX, tuvo caminos diferentes en Bolivia. Hacia 1970 este modelo de estado comenzó a ser cuestionado por el movimiento katarista aymara y, más tarde, por las organizaciones etnopolíticas de las tierras bajas reunidas en una confederación, que planteaban desde entonces la necesidad de un estado plurinacional que los representara. Las organizaciones indígenas han estado muy ligadas a los procesos políticos nacionales y han participado en los procesos electorales. El censo de 2001 indicaba que la población total era de ocho millones de personas y la población indígena más de cinco millones (66\%), sin embargo el censo de 2012 hizo descender a 40,57 el porcentaje de indígenas; disminución posiblemente atribuible a un cambio en las preguntas censales acerca de la lengua hablada y la pertenencia étnica. En 2006, la Asamblea Constituyente convocada por el gobierno avanzó hacia la estructuración de un modelo de estado plurinacional, pluricultural e intercultural, en el que los pueblos indígenas son concebidos como naciones integrantes del estado, con derechos colectivos y la posibilidad de construir autonomías territoriales (Albó, 2014). Una novedad significativa es plantear la necesaria interculturalidad del nuevo estado pluricultural, entendida no sólo como convivencia respetuosa de las diversidades sino también como forma de enriquecimiento mutuo, lo que constituye un avance notable respecto de las concepciones de otros estados nacionales sobre el pluralismo que se mantienen en el reconocimiento de hecho y mucho menos de derecho.

En Perú el censo de 2007 registró una población total de poco más de veintisiete millones de personas y una población indígena de más de once millones. Este $44 \%$ categorizado como indígena estaba distribuido en setenta y dos grupos etnolinguísticos ubicados en dos regiones internas diferenciadas: la selva amazónica con pequeños grupos que hacia 
1970 comenzaron a agruparse en organizaciones de carácter y reivindicación étnicos, y la costa, los valles interandinos y la montaña, ocupados por muchos miles de quechuas y aymaras que sufrieron procesos históricos y contemporáneos de desindianización, pasando a categorizarse y ser categorizados por la clase social de pertenencia, esto es, como campesinos. Hacia 1970, momento de surgimiento de los movimientos etnopolíticos en toda América Latina, en Perú, las orientaciones ideológicas eran homogeneizadoras de las diferencias étnicas, campesinistas y sindicalistas, coincidiendo la derecha que buscaba la integración y unidad nacionales con la izquierda que buscaba la concreción del modelo marxista de la lucha de clases, en el que el componente étnico debía desaparecer. Por ello, las organizaciones etnopolíticas, en especial de nivel macro, son recientes en el contexto nacional así como es nuevo el reconocimiento constitucional de la pluralidad cultural y el multilingüismo. Sin embargo, en el mundo andino vuelto campesino y obrero se han reproducido históricamente símbolos étnicos, que algunos candidatos presidenciales se han preocupado por revitalizar e incorporar a su discurso político, como una estrategia para llegar a y captar a los votantes campesinos-indígenas (Ossio, 2014).

Ecuador, en virtud de las importantes reformas constitucionales y el empoderamiento de las organizaciones indígenas nacionales, muestra la diversidad étnica nacional en un marco favorable a la interculturalidad en el que los indígenas son actores sociales de primer orden. Hacia 1960 y 1970 y en el contexto de la Reforma Agraria comenzó la movilización indígena moderna con marcadas propuestas agraristas y campesinistas. Al igual que en Perú, fueron los indígenas de la selva amazónica los que integraron tempranas organizaciones de corte etnopolítico en defensa de sus territorios, lenguas y culturas, como la Federación Shuar surgida en 1964 con el apoyo de los misioneros salecianos. Más tarde se creó la primera organización nacional, la Confederación de Nacionalidades Indígenas del Ecuador (CONAIE). La población total del país según el censo de 2010 ascendía a catorce millones cuatrocientas ochenta y tres mil personas y los indígenas, hablantes de seis familias lingüísticas, sumaban poco más de un millón (7,3\%), pero eran una de las fuerzas más organizadas del país. Al decir de Moreno (2014), la legislación ecuatoriana es una de las más avanzadas del continente en términos de derechos indígenas.

Chile, con una población total de dieciséis millones quinientas mil personas y una población indígena de un millón setecientas mil personas (11,11\%), según el censo de 2012 (Wikipedia, 2014), ofrece un panorama del pluralismo indígena con nueve etnias, de las cuales los mapuches son más de 600000 (Campos, 2014). En Argentina, que se ha caracterizado por las políticas genocidas y etnocidas emprendidas durante el siglo XIX y comienzos del XX contra los indígenas, el censo de 2010 registraba la existencia de un millón de personas (2,38\%), pertenecientes a numerosos grupos etnolinguísticos; entre ellos los guaraní, q’om (toba), wichi (mataco), pilagá y mapuche, dentro de una población total de 40 millones de personas. Ambos países del cono sur americano y Brasil (en el Nordeste) se caracterizan actualmente por la existencia de importantes procesos de etnogénesis. Esto es, de surgimiento de nuevos grupos indígenas o, en la mayoría de los casos, de re-surgimiento de grupos que habían resultado invisibilizados en los contextos regionales, ocultando y eventualmente "olvidando" sus orígenes étnicos, y que la historia, la antropología y la sociedad nacionales daban por extintos.

Brasil constituye una realidad diferenciada en el contexto de América Latina no sólo por las raíces históricas lusitanas sino por la importante presencia africana en su formación. Sus descendientes, los afrobrasileños, se han constituido como actores sociales diversos 
en busca del reconocimiento global de sus derechos, a través de los remanecientes de quilombos, las diversas religiones que integran los cultos afrobrasileños y las hermandades negras que funcionan como asociaciones de asistencia. Según el censo de 2010, dentro de una población total de ciento noventa y millones de personas, la población negra y mulata ascendía a noventa y siete millones, en tanto que la indígena sumaba unas novecientas mil personas $(0,47 \%)$ (Wikipedia, 2014), distribuidas en veinte familias lingüísticas y 170 lenguas, gran parte de las cuales lucha por el reconocimiento a la diversidad y la demarcación de los territorios étnicos. Brasil es el país latinoamericano que alberga la mayor diversidad indígena, con un caudal numérico pequeño en el contexto nacional, y que desarrolla numerosas políticas públicas específicas para esos pueblos indígenas en los ámbitos de la salud, la educación, la demarcación de territorios étnicos, lo que demuestra cierto grado de gobernanza de la diversidad cultural.

Álvarez (2014) nota que en contraste con el uso en Estados Unidos, que racializa el concepto multiculturalismo, en América Latina la cuestión étnica se ha clasistizado y culturalizado. Como resultado de las diferentes perspectivas en Estados Unidos el multiculturalismo encapsula las diversidades en compartimientos casi estancos, en tanto que en América Latina genera nuevos espacios de habla y de ciudadanía en cuyas bases se encuentran las luchas por el reconocimiento.

\section{Una recapitulación desde la antropologia}

Ante los diversos usos e interpretaciones existentes mi propuesta es que para referirnos con propiedad a la interculturalidad debemos aceptar por lo menos dos acepciones del término. Una, de uso común y no situacional, que se refiere genéricamente al contacto entre culturas y acepta la diferencia entre ellas, y otra, de uso literario-científico y situacional, que se refiere al contacto entre culturas diversas en el marco de la globalización, el multiculturalismo y las políticas de derechos humanos. En México el uso del término en su primera acepción no era frecuente en el siglo XX. Hacia mediados de 1980 se difundió en la segunda acepción, principalmente en el ámbito de la educación bilingüe intercultural como una conquista del indigenismo de participación, de orientación pluralista. Esto es, que el uso generalizado del término intercultural comenzó ya ligado con contextos sociopolíticos e históricos de tendencia pluralista.

Es bien sabido que las culturas se originan y transforman en contextos de contacto con otras diversas, y el estudio de esa diversidad o diferencia cultural ha sido el objeto de la antropología desde sus orígenes. Hoy llamamos interculturalidad a esta dinámica de contacto de las diversidades y durante gran parte del XX se le decía aculturación, y a sus productos culturales sincretismos, pensando tanto en la yuxtaposición de elementos culturales provenientes de las diferentes culturas como en la apropiación cultural y la construcción de nuevas unidades culturales. La antropología, y dentro de ella la etnografía, es la disciplina social que más ha estudiado el contacto entre culturas en sus diferentes modalidades desde sus antecedentes en la Antigüedad clásica, cuando los griegos registraban las singularidades de las culturas y el contacto con los bárbaros. La imagen de los "Otros" que convoca el término "bárbaro" está construida sobre conceptos prejuiciosos de la diferencia cultural y esta imagen pasó más tarde a América e influenció en gran medida la figura estigmatizada del indio que se forjó con la situación colonial. Sin embargo, no hablaremos aquí de la ideología de la barbarie ni de su contraparte, la del 
buen salvaje, presente tanto en Europa como en América, aunque minoritaria (Barabas, 2003).

Hacia 1880 los antropólogos norteamericanos comenzaron a utilizar el concepto de aculturación para referirse a procesos de contacto de una vía, de asimilación o sustitución cultural. En 1936 Redfield, Linton y Herskovitz, entre otros, definieron aculturación como aquellos fenómenos que resultan cuando dos grupos que tienen culturas diferentes entran en contacto directo y continuo, con los subsiguientes cambios en la cultura original de uno o de ambos grupos; definición realista ya que esta dinámica resulta de cualquier situación de contacto, pero que estaba todavía teñida de una visión evolucionista y unilineal de la historia para la cual las relaciones entre culturas diferentes eran concebidas como de superioridad-inferioridad. Desde este paradigma, y desde la perspectiva funcionalista, se pensó en el proceso de contacto entre indios y blancos como en un proceso de aculturación, en el cual los indios considerados culturas primitivas e inferiores iban a adquirir la cultura del grupo supuestamente superior, hasta asimilarse a la cultura dominante. En términos de la sociedad se hablaba de integración a la sociedad nacional subsumiendo las identidades alternas en la identidad nacional, objetivo del indigenismo integracionista durante muchas décadas. Sólo hacia fines de la década de 1950, cuando se dejó de pensar en sistemas sociales en permanente equilibrio, fue que los antropólogos se refirieron a otros fenómenos producidos a partir de situaciones de contacto entre culturas y, además de medir el grado de aculturación, comenzaron a estudiarse procesos de rechazo cultural, de reculturación o nativismo y de sincretismo o fusión cultural, que dan cuenta de los conflictos y las recombinaciones o yuxtaposiciones de elementos culturales propios y ajenos apropiados, que llevaban a la creación de nuevas formas culturales.

Hacia 1950 el paradigma de la antropología dinamista y sus estudios sobre la "situación colonial" y el poder en las relaciones de contacto en África (Balandier, 1951), entre otras influencias, promovieron la comprensión del proceso de contacto como desigual, marcado por las relaciones de dominio-sujeción de explotación. En la siguiente década, pero en el contexto sudamericano, se caracteriza el proceso de contacto como relaciones interétnicas conflictivas, y se construyen conceptos clave como "fricción interétnica" (Cardoso de Oliveira, 1968), "colonialismo interno" (González Casanova, 1965, Stavenhagen, 1969), "fronteras étnicas" (Barth, 1969), y "etnocidio" (Jaulin, 1970, 1972), que incorporaban las dimensiones de contraste, asimetría de poder político y económico, desigualdad, discriminación y procesos de destrucción cultural, como formas de la dinámica interétnica.

Es probablemente hacia fines de 1980, ya en plena globalización, que comienzan a utilizarse los términos intercultural e interculturalidad, aunque con diferentes significados. Uno de ellos es la acepción literal que hace referencia, como ya se dijo, al contacto entre culturas diferentes, otro es la creación de un nuevo espacio inter-cultural en cierta forma híbrido, otro más es la dinámica de relaciones de contacto propia del presente -o al menos deseable- y sustentada en la filosofía y práctica del pluralismo cultural. En ese contexto, la interculturalidad tiene que ver con la forma y la dinámica del contacto en esta época, que ya no es asimilacionista y se desea pluralista, en la que las culturas diferentes no se ven forzadas a adoptar los patrones y pautas de la cultura mayoritaria.

29 Esta interculturalidad, propia de la ideología del pluralismo cultural, supone respeto por las culturas diferentes, tolerancia, convivencia y comunicación intercultural sobre la base 
de la igualdad, para propiciar el diálogo entre culturas. En este contexto de interculturalidad en el que todos estamos involucrados, la comunicación intercultural es una forma de contacto opuesta a la aculturación y a la fricción interétnica, es la forma comunicativa del pluralismo cultural y tiene lugar en el espacio de los derechos humanos a la diversidad cultural.

En suma, y de acuerdo con sus distintos significados, interculturalidad puede ser entendida como: el contacto de hecho entre culturas, un nuevo espacio cultural, ideología, método, dinámica de las relaciones entre diferentes culturas en un contexto pluricultural y o multicultural. El tema no es nuevo, en especial para la antropología, pero sí el cambio de terminologías, ideologías y situaciones contextuales, siendo así que interculturalidad debiera dar nombre a otra situación de contacto, no desigual sino igualitario de las diferencias, que se funde en la ideología del pluralismo y el cultivo de las diferencias y sus derechos.

31 La interculturalidad en América Latina no se ha desenvuelto históricamente, ni se desenvuelve al menos por ahora, en un marco de relaciones de convivencia tolerante y respetuosa entre los pueblos originarios y la diversa población no indígena nacional, y menos aún en el marco de políticas favorecedoras del pluralismo cultural, sino en uno de relaciones discriminatorias, racistas y explotadoras. En el mejor de los casos, la interculturalidad forma parte del discurso ideológico y político de sectores respetuosos del pluralismo, que no tiene gran repercusión en términos de las leyes y defensa de derechos étnicos.

Bien sabemos entonces que en el seno de nuestra realidad constituida la interculturalidad y el pluralismo son utopías, es decir, realidades sin o con escasa concreción actual, pero dimensiones de lo posible, retos a la transformación de ideologías y prácticas en el futuro. Más allá de los reconocimientos formales en las leyes y de la presencia en cierta ideología social, las relaciones interculturales pluralistas pocas veces se dan en el presente de nuestros países. De allí que, la pregunta que se plantea es cómo referirnos a la dinámica real de contacto entre culturas que se desenvuelve en un espacio de relaciones injustas: ¿cómo pluralismo o interculturalidad desiguales? ¿Sin embargo, no es una contradicción hablar de interculturalidad desigual si hemos definido interculturalidad como la ideología y la praxis del pluralismo cultural, que supone un determinado tipo de relación, de dinámica, respetuosa de la alteridad y sus derechos?. La disyuntiva no es fácil; no obstante, desde mi perspectiva el concepto interculturalidad como dinámica actual del contacto debe transformarse, ampliarse, para dar explicaciones a las realidades sociales desiguales y estigmatizadoras que persisten en el contexto de la globalización y del pluralismo desigual.

\section{BIBLIOGRAFÍA}

ALBÓ, Xavier (2014 en prensa), “Bolivia. Plurinacional e Intercultural”, Coord. A. Barabas, Multiculturalismo e Interculturalidad en América Latina, México, INAH. 
ÁLVAREZ, Gabriel (2014 en prensa), “Indios, negros y ciudadanos. Luchas multiculturales por el reconocimiento (Brasil)”, Coord. A. Barabas, Multiculturalismo e Interculturalidad en América Latina, México, INAH.

AZURMENDI, Mikel (2002), "La invención del multiculturalismo”, en Diario ABC, España.

BALANDIER, George (1951), “La situation coloniale: aproche théorique”, en Cahiers Internationaux de Sociologie, vol. IX, Paris.

BARABAS, Alicia (1989), Utopías Indias. Movimientos sociorreligiosos en México, México, Grijalbo (1ª edición).

BARABAS, Alicia (1996), "La rebelión zapatista y el movimiento indio en México”, Série Antropología, Departamento de Antropología, Universidade de Brasilia, Brasilia.

BARABAS, Alicia (2003), "Imaginarios de la alteridad: la construcción del indio como bárbaro", en Anuario Antropológico 2000-2001, DAN Universidad de Brasilia, Río de Janeiro, ed. Tempo brasileiro.

BARABAS, Alicia (2005), "Movimientos indígenas y etnografía: un balance del siglo XX”, Coord. G. Artís, Encuentro de Voces. La etnografía de México en el siglo XX, México, INAH.

BARABAS, Alicia (2014a),"Etnoterritorios: legislaciones, problemáticas y nuevas experiencias", Pueblos Indígenas, Estados nacionales y fronteras, Coords. Trinchero, Campos y Valverde, FFL-UBA (Argentina), UAHC (Chile), Clacso (Ecuador).

BARABAS, Alicia (2014b, en prensa), (Coordinadora) Multiculturalismo e Interculturalidad en América Latina, México, INAH.

BARTH, Frederik (1969), Ethnic groups and boundaries, Little Brown an Co., Boston.

BARTOLOMÉ, Miguel (2006), Procesos Interculturales. Antropología Política del pluralismo cultural en América Latina, México, Siglo XXI (1ª edición).

CAMPOS, Luis (2014 en prensa), "Descubriendo la multiculturalidad. El caso chileno", Multiculturalismo e Interculturalidad en América Latina, Coord. A. Barabas, México, INAH.

CARDOSO DE OLIVEIRA, Roberto (1968),"Problemas e hipóteses relativos a fricção interétnica: sugestões para uma metodologia", América indígena, vol. XXVIII, \# 2, México.

DIEZ-MEDRANO, Juan (2002), “Thematic Introduction”, International Journal on Multicultural Societies, vol. 4 , \# 1 .

FORNET-BETANCOURT, Raúl (1994), Hacia una filosofía intercultural latinoamericana, San José, Costa Rica, DEI.

FORNET-BETANCOURT, Raúl (1998), “Supuestos filosóficos del diálogo intercultural”, Polylog\# 1, Viena.

GONZÁLEZ CASANOVA, Pablo (1965), Sociología de la explotación, México, Siglo XXI.

JAULIN, Robert (1973), La Paz Blanca: introducción al etnocidio, Argentina, Tiempo Contemporáneo, (en francés, 1970).

JAULIN, Robert (1976), El etnocidio a través de las Américas, comp., México, Siglo XXI, (en francés, 1972).

KYMLICKA, Will (1996), Ciudadanía multicultural. Estado y Sociedad, España, Paidós.

KYMLICKA, Will (2003), La política vernácula: nacionalismo, multiculturalismo y ciudadanía, Barcelona, Paidós.

MIRA, Nuria (2001), “Las máscaras del multiculturalismo”, Scripta Nova \# 94, Barcelona. 
MORENO, Segundo (2014, en prensa), “Antropología abierta, antropología ambigua. Tendencias actuales de la antropología ecuatoriana”, Multiculturalismo e Interculturalidad en América Latina, Coord. A. Barabas, México, INAH.

OEHMICHEN, Cristina (2014, en prensa), "El pluralismo cultural en México", Multiculturalismo e Interculturalidad en América Latina, Coord. A. Barabas, México, INAH.

OSSIO, Juan (2014, en prensa), "Multiculturalidad e indianismo en el Perú", Coord. A. Barabas, Multiculturalismo e Interculturalidad en América Latina, México, INAH.

PAREK, Bhiku (2000), Rethinking Multiculturalism: cultural diversity and political theory, Reino Unido, Palgrave.

PAREK, Bhiku (2004), “¿Cuál es el multiculturalismo?”, página web indiaseminar.com/1999/484/.

REDFIELD, Robert; LINTON, Ralph y HERSKOVITZ, Melville (1936), "Memorandum of the study of acculturation", American Anthropologist, vol. XXXVIII, USA.

REX, John y SINGH, Gurharpal (2003), "Pluralism and Multiculturalism in Colonial and PostColonial Society”, International Journal on Multicultural Societies, vol. V, \# 2.

ROULAND, Norbert; PIERRÉ-CAPS, Stéphane et al. (1999), Derecho de minorías y de pueblos autóctonos, México, Siglo XXI.

STAVENHAGEN, Rodolfo (1969), Las clases sociales en las sociedades agrarias, México, Siglo XXI.

TURNER, Terence (1993), “Anthropology and multiculturalism: what is anthropology that multiculturalist should be mindful of it", Cultural Anthropology, vol. 8 \# 4, EUA.

VERTOVEC, Steven (2003), “Desafíos trasnacionales al 'nuevo' multiculturalismo”, Migración y Desarrollo 1.

VILLORO, Luis (1998), Estado plural, pluralidad de culturas, México, Paidós- UNAM.

WIKIPEDIA (2014), Censos oficiales por países de América Latina. Anexo: Pueblos Indígenas de América.

\section{NOTAS}

1. Entre los textos consultados pueden mencionarse: Turner, 1993; Fornet- Betancourt, 1994, 1998; Kymlicka, 1996, 2003; Villoro, 1998; Mahajan, 1999; Parekh, 2000; Mira, 2001; Diez-Medrano, 2002; Rex y Singh, 2003; Azurmendi, 2003; Bartolomé, M., 2006.

\section{RESÚMENES}

Este artículo trata de precisar los diversos significados de los conceptos multiculturalismo, pluralismo cultural e interculturalidad, para arribar a usos más pertinentes en relación con los panoramas de la diversidad cultural en América Latina, poniendo la atención en la situación de los Pueblos Originarios en los contextos nacionales. 
Este artigo especifica os diversos significados dos conceitos de multiculturalismo, pluralismo, cultura e interculturalidade, para chegar a usos mais pertinentes relativamente aos panoramas da diversidade cultural na América Latina, dando atenção especial à situação dos Povos Originários nos contextos nacionais.

This paper defines the multiple meanings of concepts such as multiculturalism, cultural pluralism and interculturality in order to arrive at more pertinent uses in relation with the contexts and realities of cultural diversity in Latin American countries, focusing on the situation of the Indigenous Peoples into the national contexts.

\section{ÍNDICE}

Keywords: Multiculturalism, cultural pluralism, interculturality, Indigenous Peoples Palabras claves: Multiculturalismo, pluralismo cultural, interculturalidad, Povos Originarios Palavras-chave: interculturalidade

\section{AUTOR}

\section{ALICIA M. BARABAS}

SNI-CONACYT, Instituto Nacional de Antroplogí a y Historia - Oaxaca \& CONACYT. Enderezo de correspondencia: Pino

Suárez 715, cp. 68000, Oaxaca, Oax., México. Teléfono: (0052) (951) 5200883

barbar2@prodigy.net.mx 